Article

\title{
Validating the Real-Time Performance of Distributed Energy Resources Participating on Primary Frequency Reserves
}

\author{
Niko Karhula ${ }^{1, *}$, Seppo Sierla ${ }^{1}$ (D) and Valeriy Vyatkin ${ }^{1,2,3}$ \\ 1 Department of Electrical Engineering and Automation, School of Electrical Engineering, Aalto University, \\ FI-00076 Espoo, Finland; seppo.sierla@aalto.fi (S.S.); valeriy.vyatkin@aalto.fi (V.V.) \\ 2 Department of Computer Science, Electrical and Space Engineering, Luleå University of Technology, \\ 97187 Luleå, Sweden \\ 3 International Research Laboratory of Computer Technologies, ITMO University, 197101 St. Petersburg, Russia \\ * Correspondence: niko.karhula@aalto.fi
}

Citation: Karhula, N.; Sierla, S.; Vyatkin, V. Validating the Real-Time Performance of Distributed Energy Resources Participating on Primary Frequency Reserves. Energies 2021, 14 , 6914. https://doi.org/10.3390/ en14216914

Academic Editor: Luis

Hernández-Callejo

Received: 23 September 2021

Accepted: 15 October 2021

Published: 21 October 2021

Publisher's Note: MDPI stays neutral with regard to jurisdictional claims in published maps and institutional affiliations.

Copyright: (c) 2021 by the authors. Licensee MDPI, Basel, Switzerland. This article is an open access article distributed under the terms and conditions of the Creative Commons Attribution (CC BY) license (https:/ / creativecommons.org/licenses/by/ $4.0 /)$.

\begin{abstract}
A significant body of research has emerged for adapting diverse intelligent distributed energy resources to provide primary frequency reserves (PFR). However, such works are usually vague about the technical specifications for PFR. Industrial practitioners designing systems for PFR markets must pre-qualify their PFR resources against the specifications of the market operator, which is usually a transmission system operator (TSO) or independent system operator (ISO). TSO and ISO requirements for PFR have been underspecified with respect to real-time performance, but as fossil-fuel based PFR is being replaced by various distributed energy resources, these requirements are being tightened. The TSOs of Denmark, Finland, Norway, and Sweden have recently released a joint pilot phase specification with novel requirements on the dynamic performance of PFR resources. This paper presents an automated procedure for performing the pre-qualification procedure against this specification. The procedure is generic and has been demonstrated with a testbed of light emitting diode (LED) lights. The implications of low bandwidth Internet of Things communications, as well as the need to avoid abrupt control actions that irritate human users, have been investigated in the automated procedure.
\end{abstract}

Keywords: aggregator; primary frequency reserve; LED lighting; demand response; NarrowBandInternet of Things (NB-IoT); ancillary service

\section{Introduction}

Demand response (DR) refers broadly to techniques for managing power consumption to balance the power grid. One categorization can be made based on whether the DR is planned of time or whether it is triggered in real time to react to an imbalance that has already occurred in the power grid. The latter category includes ancillary services, such as the rapid activation of power producing or consuming units for the purpose of coping with grid frequency deviations [1]. Markets for procuring such frequency based ancillary services are operated by independent system operators (ISOs) in the US and transmission system operators (TSOs) in many other regions of the world [2]. Although different names are used in different regions of the world, the fastest acting frequency reserves are generally called primary frequency reserves (PFR). As fossil fuel-based generators are being replaced with wind and photovoltaic production, the resulting reduction in grid inertia is becoming a threat to power system stability under the existing allowable delays for PFR [3]. TSOs in Finland, Sweden, Norway, and Denmark are among the first to react to this problem by new specifications for a joint PFR market frequency containment reserves for normal operation (FCR-N) [4]. In most European countries, FCR is the name of the PFR market. In northern Europe, there are two such markets: FCR-N and FCR-D. FCR-N is activated when the frequency deviates outside the $49.99-50.01 \mathrm{~Hz}$ range. FCR-D is activated only when the frequency deviates outside the $49.9-50.1 \mathrm{~Hz}$ range. The specification [4] provides 
the detailed technical requirements for both markets. The new specifications will be used in an upcoming piloting phase, and they differ from the current specification, which does not specify real-time requirements for how power production or consumption should be adjusted in response to grid frequency deviations [5]. The new specifications introduce two new kinds of requirements: dynamic performance requirements and stability requirements [4]. To bridge the gap between research, development, and implementation, this paper will investigate the impact of the new requirements on the real-time considerations that must be taken into account by developers and implementers of PFR with distributed energy resources. It is expected that uptake of research by the developer community will be higher, if research prototypes have been assessed according to such requirements.

PFR have traditionally been provided by fossil fuel based spinning reserves [6]. In the last years, a growing body of research has emerged for exploiting various intelligent distributed energy resources for PFR [7]. Only a minority of these, such as [8], consider the impact on the stability of the power grid. As the performance requirements and stability requirements from TSOs are very new [4], there is a lack of research on how to meet these requirements with intelligent distributed energy resources.

Each type of intelligent distributed energy resource has its own constraints that must be taken into account when using them for PFR. The FCR-N technical requirements [4] specify two categories of distributed energy resources that can be used to provide the reserve: distributed generators and controllable loads. The specifications for these are mirror images of each other. For example, in overfrequency situations, a generator should reduce its generation whereas a controllable load should increase its consumption. This paper will focus on the case of a controllable load. In this paper, light emitting diode (LED) lighting will be taken as an example. One of the breakthroughs of LED technology is the ability of LED luminaires to undergo frequent power adjustments without adverse effect to the lifetime of the luminaire. This ability has prompted the development of intelligent lighting networks that react to changes in environmental conditions and traffic [9], with applications for indoor [10] and outdoor [11] lighting. However, the dimming must be executed without causing unacceptable disturbance to humans [12]; in this paper the use of a ramp for dimming and brightening the LED luminaire will be investigated with respect to the PFR performance requirements and stability requirements.

If PFR are being provided through the aggregation of geographically distributed energy resources, communication delays should also be taken into consideration to ensure that PFR performance requirements and stability requirements are met. In the case of a system with a high number of small loads, aggregating them over the Internet for the purpose of providing PFR is a viable strategy $[13,14]$. For low power IoT applications, narrowband-IoT (NB-IoT) is an economical communication solution between the aggregator and the energy resources. The observed latencies in the range 2 to $8 \mathrm{~s}$ are sufficient for demand response applications in general [15], and this paper will investigate the impact of such delays on meeting PFR performance requirements and stability requirements. If sufficiently low latencies cannot be achieved, it is possible to avoid the need for real-time communication between the aggregator and the resources by installing grid frequency measurement equipment alongside each distributed energy resource [16]. However, a significant cost is involved in such installations, which is difficult to justify against the typical price levels from PFR markets $[17,18]$, so there is motivation to investigate affordable IoT communication solutions with adequate real-time performance for PFR. This paper makes the following contributions:

1. Significant manual work is required to run the prequalification tests specified by the new Nordic TSOs PFR performance requirements and stability requirements [4]. A methodology for automating this process is presented;

2. Several kinds of distributed energy resources are advantageously adjusted with a ramp, to avoid disturbance to humans or strain to the resource. The impact of using various ramp rates is studied with respect to PFR performance requirements and stability requirements [4]; 
3. Communication delays are injected to the system to identify acceptable delays with respect to PFR performance requirements and stability requirements [4].

\section{Related Work}

Many innovative applications for distributed energy resources lack regulatory or financial motivation to consider impacts on grid stability. For example, Nefedov et al. [19] optimize the use of local photovoltaic production and local battery storage simply to minimize $\mathrm{kWh}$ of electricity bought from the grid. Lu et al. [20] note that demand response schemes based on day-ahead prices are not suited for reacting to unforeseen variations in grid conditions. A partial consideration of grid impact involves reduction in peak demand as part of a demand response scheme [21]. However, demand response solutions are prone to causing consumption peaks before or after the demand response period, unless specific countermeasures are taken [1,22].

Since PFR react to grid frequency variations in real-time, developers of PFR applications obviously need to consider real-time grid impact. Unfortunately, until recently, PFR market operators have underspecified real-time performance requirements (e.g., [5]), so these are not explicitly addressed by some papers on PFR (e.g., [23]). Other authors apply heterogeneous approaches for real-time grid impacts assessment. Lee et al. [24] analyze the impact of large-scale deployment of battery reserves to reduce frequency volatility. Although this demonstrates some beneficial grid impacts, these works do not address PFR market operators' technical requirements. Liu et al. [8] quantify impacts in terms of rate of change of frequency (ROCOF), which is important from the perspective of complying with grid codes, but not directly related to PFR technical requirements. Further, significant portion of research considers only stationary requirements and simplistic time-domain dynamic requirements, such as time until partial or full capacity activation or energy exchange during a specified time frame following frequency deviation. Such examples include [25-27].

The stationary requirement of FCR (i.e., the European PFR market), is considered in applications for paper mills [28], heat pumps [29], battery storages [30,31], wind power [32], refrigerators [33], and uninterruptible power supply (UPS) systems [34]. Similar work has been completed with battery storages for the UK PFR market (Enhanced Frequency Response) [35]. These approaches satisfy current specifications, e.g., [5], but do not consider dynamic performance requirements and stability requirements that TSOs are piloting at the time of writing [4]. Validation against these new requirements necessitates empirical validation by measuring power output in response to test frequency signals [36]. Neither of these approaches can be integrated in a straightforward way to the multi-objective optimization approaches used in the previous works [28-32]. However, the control approaches based on logic algorithms [35] and proportional integral-derivative (PID) control [33] could be more applicable to the new validation procedures [36], which could inform the adjustment of the control parameters, until the validation is passed. Such an approach would require frequent repetition of the validation procedures at research and development time, which motivates the contribution 1 in Section 1 related to automating these procedures.

The PFR research community has not yet addressed the possibility of incorporating automatic testing of real-time requirements in the research and development phase. It is notable that implementations must satisfy all TSO specified requirements in order to receive permission to participate on the PFR market. Automatic validation of these requirements throughout the lifecycle of the system, starting from the research phase, would significantly help bridge the gap between research, development and implementation, as discussed further in Section 6. It is notable that automatic testing has established itself in other technical disciplines. In the software community, techniques for automatically running a suite of tests is called regression tests [37-39], and sophisticated tools for this purpose are available [40]. A development style in which regression testing is used for continuous validation is known as test-driven development [41], enabling the early detection of features that would be considered faults in the implementation phase [42]. However, the application of these 
techniques to the smart grid domain is not straightforward, due to the need to control and measure physical devices and systems. Researchers in the industrial automation domain have applied regression testing $[43,44]$ and test-driven development [45-48], and other similar approaches $[49,50]$ in such an environment. With respect to contribution 1 in Section 1, the system and methodology presented in this paper can be seen as an automated regression testing environment for systems being researched, developed, and implemented for PFR markets. Thus, this research enables further research on test-driven development to further bridge the gap between research, development, and implementation in this area.

\section{Methodology}

\subsection{Requirements}

In this article, power refers to active power. The TSOs specify their requirements for PFR in terms of active power [4].

\subsubsection{Stationary Performance Requirement}

If, at any moment in time, power production exceeds power consumption, the power grid frequency will exceed the rated frequency, which is $50 \mathrm{~Hz}$ in northern Europe. Similarly, when consumption exceeds production, frequency will drop below $50 \mathrm{~Hz}$. The purpose of PFR is to quickly react to such deviations and to adjust power production or consumption so that the frequency will be brought back to $50 \mathrm{~Hz}$. The magnitude of the adjustment should be proportional to the magnitude of the frequency deviation. FCR-N specifies this as a stationary performance requirement. The requirement is given for power generators, so that generation should be reduced when frequency exceeds $50 \mathrm{~Hz}$ and that generation should be increased when frequency drops below $50 \mathrm{~Hz}$. The specification states that the behavior should be vice-versa for controllable loads participating on FCR-N, so the requirement in Figure 1 has been constructed by mirroring the requirement for generators presented in [4]. The blue line is the mandatory target response, and the shaded area specifies the region of permissible outcomes. Deviations away from the blue line within the shaded area are expected, if the system is controlling relay connected loads. This stationary performance requirement is very similar to the requirements that are currently in force [5]. However, Figure 1 does not capture an element of time, so innovative solutions for providing PFR with distributed energy resources may have an adverse effect on the stability of the grid, even if they are in compliance with the stationary requirement. For this purpose, the new specification [4] introduces additional dynamic performance requirements and stability requirements, which are not present in the specification that is currently in force [5].

\subsubsection{Dynamic Performance Requirement}

The dynamic performance requirement is defined by Equation (1), where $s$ is the complex frequency, $F(s)$ is the transfer function of the system of distributed energy resources that have been aggregated to provide FCR-N, $G_{a v g}(s)$ is the transfer function of the power system and $D(s)$ is a transfer function describing the disturbance profile that FCR-N shall balance.

$$
\left|\frac{G_{a v g}(s)}{1-F(s) G_{a v g}(s)}\right|<\left|\frac{1}{D(s)}\right|
$$

The transfer function of the FCR-N providing system of distributed energy resources is determined on the basis of tests in which sinusoidal test signals are compared with sinusoidal output signals. The sinusoidal input is generated by signal generator hardware or alternatively in software. In case of a hardware generated signal, a frequency measuring device measures the signal and then provides the measurements to the controller of the FCR-N resource. However, a software-generated signal is used directly as the input to the controller. 


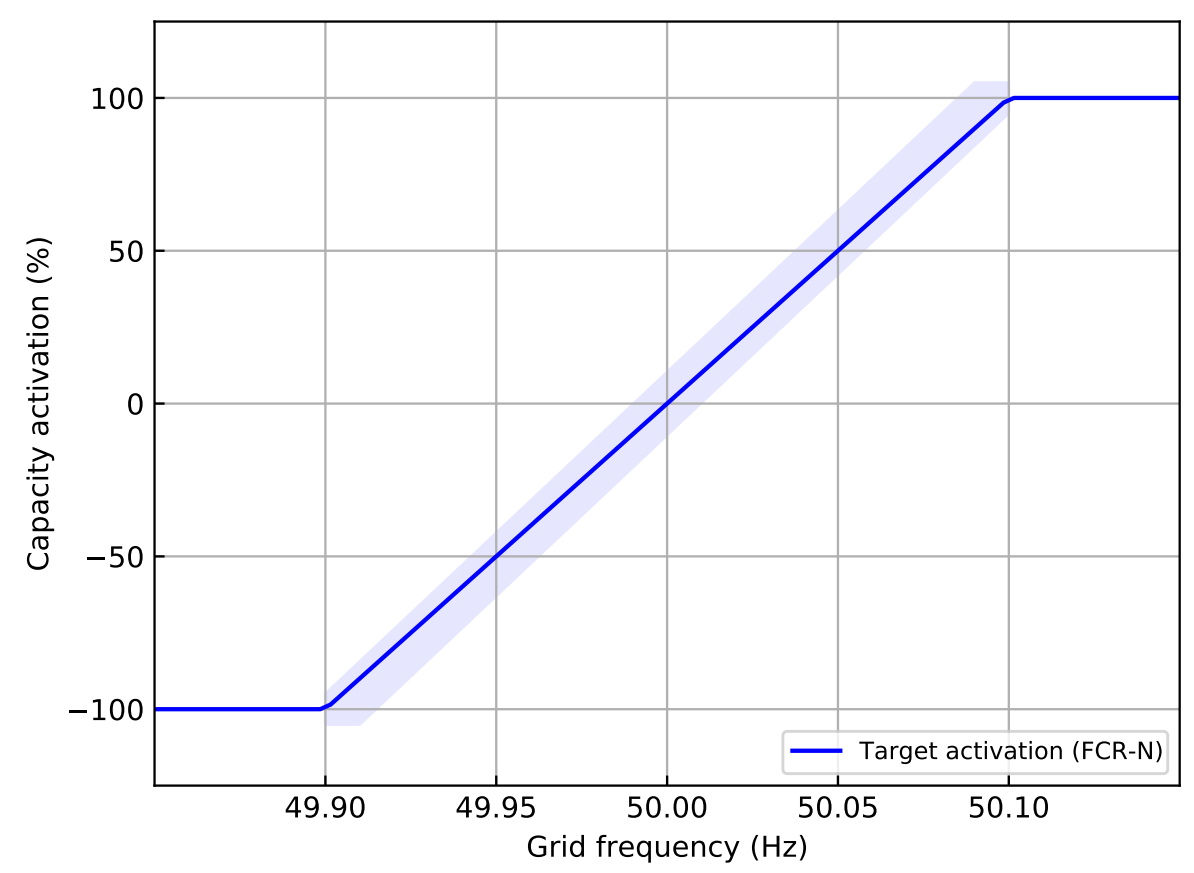

Figure 1. FCR-N stationary performance requirement (adapted from [4]).

Active power is measured at a sampling rate of at least $5 \mathrm{~Hz}$, as required by the specification [4], and recorded into a log file for subsequent analysis. Each test must run until at least five periods of stable sinusoidal output have been measured and logged. Seven tests must be performed, so that the time periods for the sinusoidal inputs shall be $10,15,25,40,50,60,70 \mathrm{~s}$, respectively. Henceforth, such a group of tests, as required by the specification [4], is referred to as a test sequence. A least-squares fit is performed for each sinusoidal output in order to determine the gain and phase shift with respect to the input. The sine function that is fitted to the active power measurements is of the form

$$
y(t)=A \sin \left(\frac{2 \pi}{T} t+\phi\right)+P_{s p}
$$

where $A$ is the gain, $\phi$ is the phase shift, $T$ is the time period of the input and $P_{s p}$ is the active power setpoint, which refers to the target power corresponding to the nominal grid frequency of $50 \mathrm{~Hz}$. Thus, gain and phase shift are free variables in the least-squares problem and the best fitting values can be searched for by numerical optimization methods. Figure 2 shows an example least-squares fit to active power measurements.

The gain and phase shift values define the frequency response of the FCR-N providing entity for a finite number of input frequencies. A Bode plot may be constructed from the frequency response data, enabling visual assessment of the dynamic behavior of the FCR-N providing entity. An ideal FCR-N providing entity has unity gain and minimal phase shift for each input frequency, indicating rapid and precise activation of reserve capacity. However, reserve capacity activation is often imperfect and may have undesirable impact on the power grid, since a FCR-N providing entity is in closed-loop with the power grid as shown in Figure 3. In order for the closed-loop system to have sufficient dynamic performance, Equation (1) must hold. The equation is applicable to frequency response data; however, only for the input frequencies which were used in the sine in sine out tests. Thus, the grid transfer function, $G_{a v g}(s)$, must be evaluated at these input frequencies. Evaluation of the left-hand side in Equation (1) then provides closed-loop frequency response data, which is linearly interpolated. Then, the gain is computed for all frequencies. The gain for each input frequency, including the interpolated frequencies, must be less than the gain of the disturbance profile defined on the right-hand side of Equation (1). 


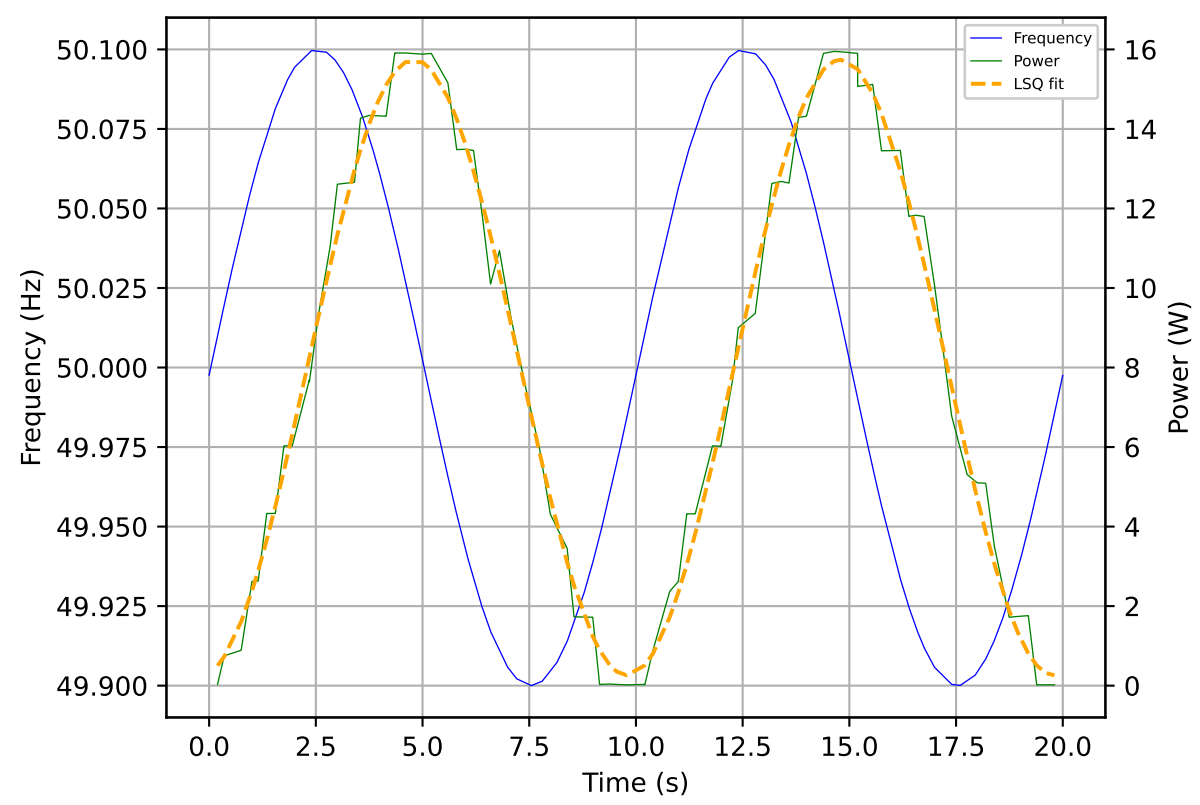

Figure 2. An example least-squares fit (orange curve) to reserve active power measurements (green curve). The blue curve is the sinusoidal input signal.

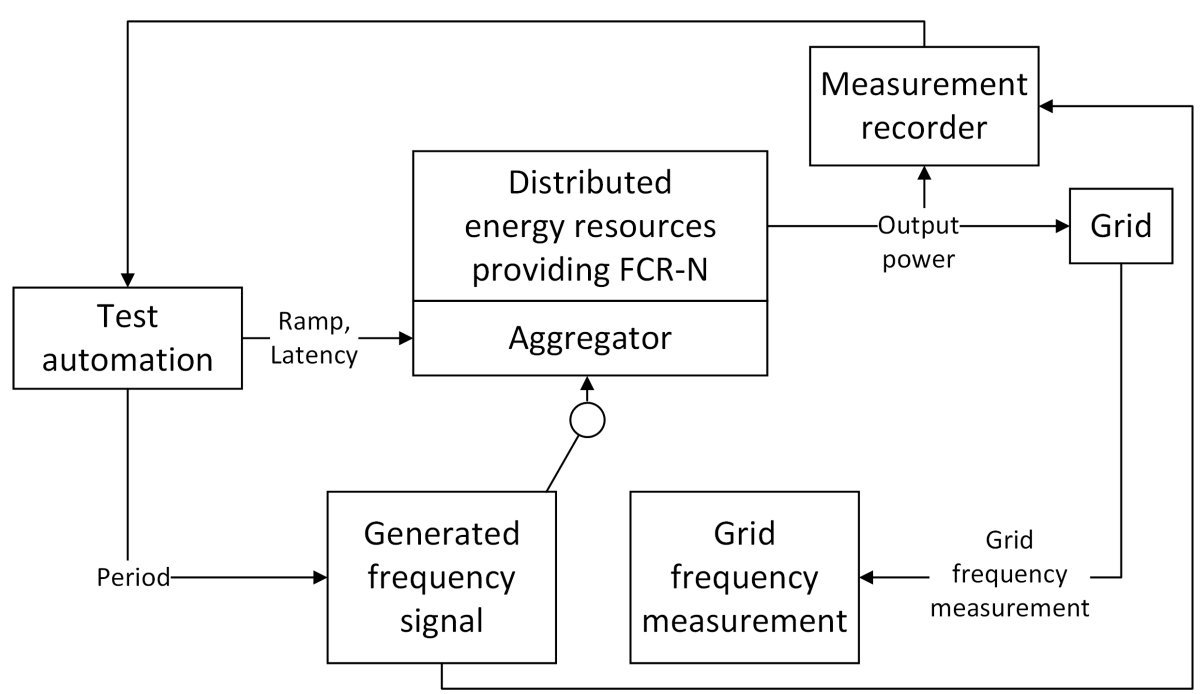

Figure 3. Setup for validation of requirements (adapted from [4]).

Dynamic performance is additionally assessed with a step test. In the step test, six step inputs are injected to the system and the step responses are logged. The applied step inputs are from $50.00 \mathrm{~Hz}$ to $50.05 \mathrm{~Hz}, 50.05 \mathrm{~Hz}$ to $50.00 \mathrm{~Hz}, 50.00 \mathrm{~Hz}$ to $49.90 \mathrm{~Hz}, 49.90 \mathrm{~Hz}$ to $50.00 \mathrm{~Hz}, 50.00 \mathrm{~Hz}$ to $50.10 \mathrm{~Hz}$, and $50.10 \mathrm{~Hz}$ to $50.00 \mathrm{~Hz}$. The first two steps are performed to include the effects of any backlash [36]. For the remaining steps, four quantities of interest must be determined: activated power and energy $60 \mathrm{~s}$ after the input, activated power $180 \mathrm{~s}$ after the input and steady-state power. In order to pass the test, the following conditions must be satisfied for each of these steps [36].

1. $\left|\Delta P_{60 s}\right| \geq 0.63\left|\Delta P_{s s}\right|$

2. $\left|\Delta P_{180 s}\right| \geq 0.95\left|\Delta P_{S S}\right|$

3. $\left|\Delta E_{60 s}\right| \geq 24 s\left|\Delta P_{s s}\right|$

\subsubsection{Dynamic Stability Requirement}

The dynamic stability of reserves participating in FCR-N and FCR-D is assessed with a Nyquist plot constructed for the open loop system $F(s) G(s)$, where $F(s)$ is the transfer 
function model of a FCR-N reserve resource and $G(s)$ is the transfer function of the power grid. The dynamic stability requirement is satisfied if the Nyquist plot does not cross the real axis on the left-hand side of the Nyquist point or enter the circle with a radius of 0.43 centered at the Nyquist point.

\subsection{Setup for Validation of Requirements}

Figure 3 shows a conceptual view of the setup used to validate the requirements. An aggregator is responsible for controlling a group of distributed energy resources according to the requirements in Section 3.1. The input to the aggregator is a frequency signal. In validation mode, the aggregator receives an artificially generated signal, which may be generated either by software or by a signal generator device [36]. In this paper, a software generated signal will be used. It is notable that there is no feedback connection from the power grid. Once the system has been validated, the aggregator switches to using a signal generated by a power grid frequency measurement device.

The specification [4] requires that the frequency measurement has an accuracy of at least $10 \mathrm{mHz}$ and a resolution of at least $1 \mathrm{mHz}$. These requirements are satisfied by the device in question (Sicam P50) [51]. Accuracy of the power measuring IC is sufficient (approximately $0.5 \%$ at $25^{\circ} \mathrm{C}$ [52]), whereas resolution is approximately twice the requirement. However, percentage resolution is of little relevance as the controllable loads have such a low rated power.

In our research, the validation setup does not use any communication links that are unreliable. The setup has been designed so that the latencies for transmitting any control signals are negligible. For testing purposes, the 'Test automation' unit launches the reserve system defining an artificial latency parameter. Then, during system operation, received network messages are delayed by suspending the message handling thread for the specified duration. Once the thread continues execution and processes the received message, a response message may be created. Sending of the response message is then delayed in the same manner.

\subsection{Validation Methodology}

Validating the requirements in Section 3.1 on the setup in Section 3.2 requires the generation of a large number of test frequency signals, recording the output power, storing the values, performing the computations and plotting the outcome. In this section, an automated procedure is presented (contribution 1 in Section 1). The procedure is first performed so that the power adjustment is performed immediately according to Figure 1. Since the immediate adjustment may stress devices or irritate human users, a gradual adjustment with a ramp will be investigated next. Several ramp rates are investigated to identify the slowest ramp which is still acceptable with respect to the requirements in Sections 3.1.1 and 3.1.2 (contribution 2 in Section 1). Finally, latencies will be artificially injected to determine the maximum allowable communication latencies between the grid frequency measurement device, aggregator, and geographically distributed resources (contribution 3 in Section 1). Sultania et al. [15] found that NB-IoT enabled devices can be controlled for demand response purposes with a maximum latency less than $8 \mathrm{~s}$ and $2 \mathrm{~s}$, within a deep-indoor environment and an outdoor environment, respectively. Thus, our setup will investigate latencies of up to $10 \mathrm{~s}$.

Figure 4 presents a unified modeling language (UML) activity diagram that defines our automatic procedure for conducting the tests in the setup introduced in Section 3.2. In the activity diagram notation, the vertical partitions are swimlanes and they map the activities in the partition to the component named at the top of the partition. These are the same components as in Figure 3. Under 'Distributed energy resources', two groups of resources are shown by way of example. Such a grouping is used in our case example. A validation process begins when the test automation unit initializes the aggregator and sets the artificial latency and other parameters, such as the slope parameter associated with the ramp controller. The unit also initializes the software-based signal generator, which generates 
the sinusoidal test input signals. The aggregator then initializes the distributed energy resources over a network and waits until the resources respond, indicating successful initialization. The aggregator will then run a control loop at least with the cycle time of $5 \mathrm{~Hz}$. The test automation unit logs each test in a CSV-file, and upon detecting the end of a test it reinitializes the software-based signal generator. If a test sequence is finished, then the aggregator is also reinitialized with different parameters. After each test sequence has been finished, the log files are processed and analyzed. Finally, a report summarizing the test results is constructed.

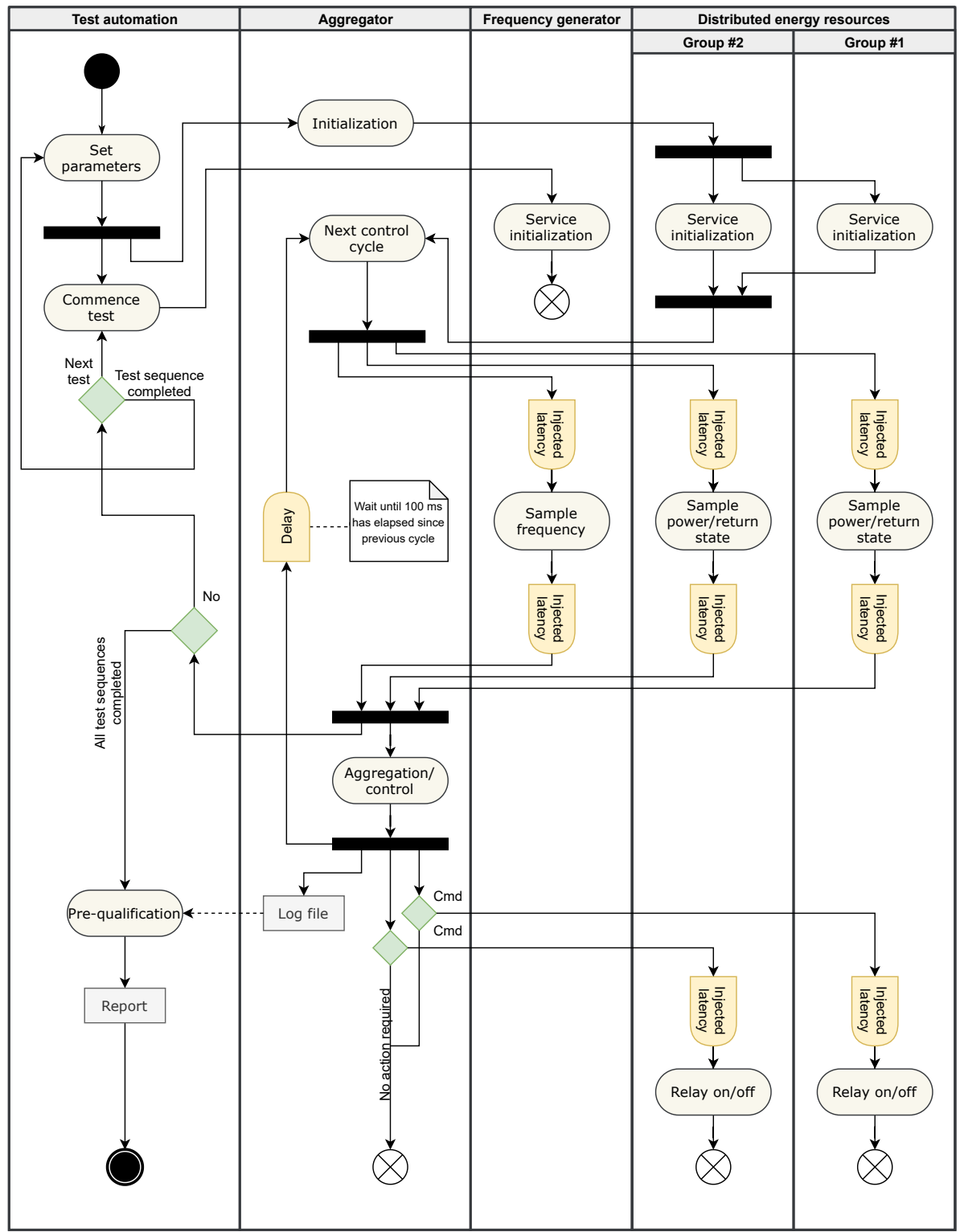

Figure 4. UML activity diagram depicting the validation setup introduced in Section 3.2.

As discussed in Section 3.1.2, each test sequence consists of seven tests: one step and six sine in sine out tests. The test sequence is performed multiple times with different reserve system parameters.

\section{Experimental Setup}

The experimental setup, shown in Figure 5, consists of two groups of distributed energy resources. Each group consists of five individual on-off controllable LED luminaires (Figure 6b), relays that switch them on or off (Figure 6c), a Raspberry Pi embedded computer and a current sensing device, which continuously computes the total power con- 
sumption of the five LED luminaires (Figure 6b). In addition, aggregation and frequency measurement are performed by separate subsystems. The aggregator consists of a single embedded computer, which can be seen at the bottom left corner in Figure 5. Frequency measurement is performed by a dedicated device, shown in Figure 6a, which is used in the operational system but not in the validation phase. The measurements are preprocessed by an embedded computer, which communicates the measurements to the aggregator. Communication happens over a low latency ad-hoc network (layer 2 network switch seen in Figure 5). In order to simulate higher latencies, such as what may occur with NB-IoT, latencies are injected in software to all messages that cross from one embedded computer to another.

Figure 7 shows the experimental setup in a block diagram. Digital control signals are exchanged between the aggregator and the embedded computers. Measurements are read over I2C or RS485 Modbus buses in the case of power and frequency, respectively. These signals are denoted by the digital measurement signal. An electrical control signal is used between the embedded computer and the relay module to emphasize that the GPIO is energizing the relay coils.

The testbed is used in two different modes:

1. The relay contacts are permanently closed and all LEDs are continuously controlled by a PWM LED driver;

2. The relays are controlled by the Raspberry Pi and the PWM LED driver supplies a constant $12 \mathrm{~V}$ signal.

These two modes allow tests to be run with the ramp controller and the aggregation logic on the same physical setup.

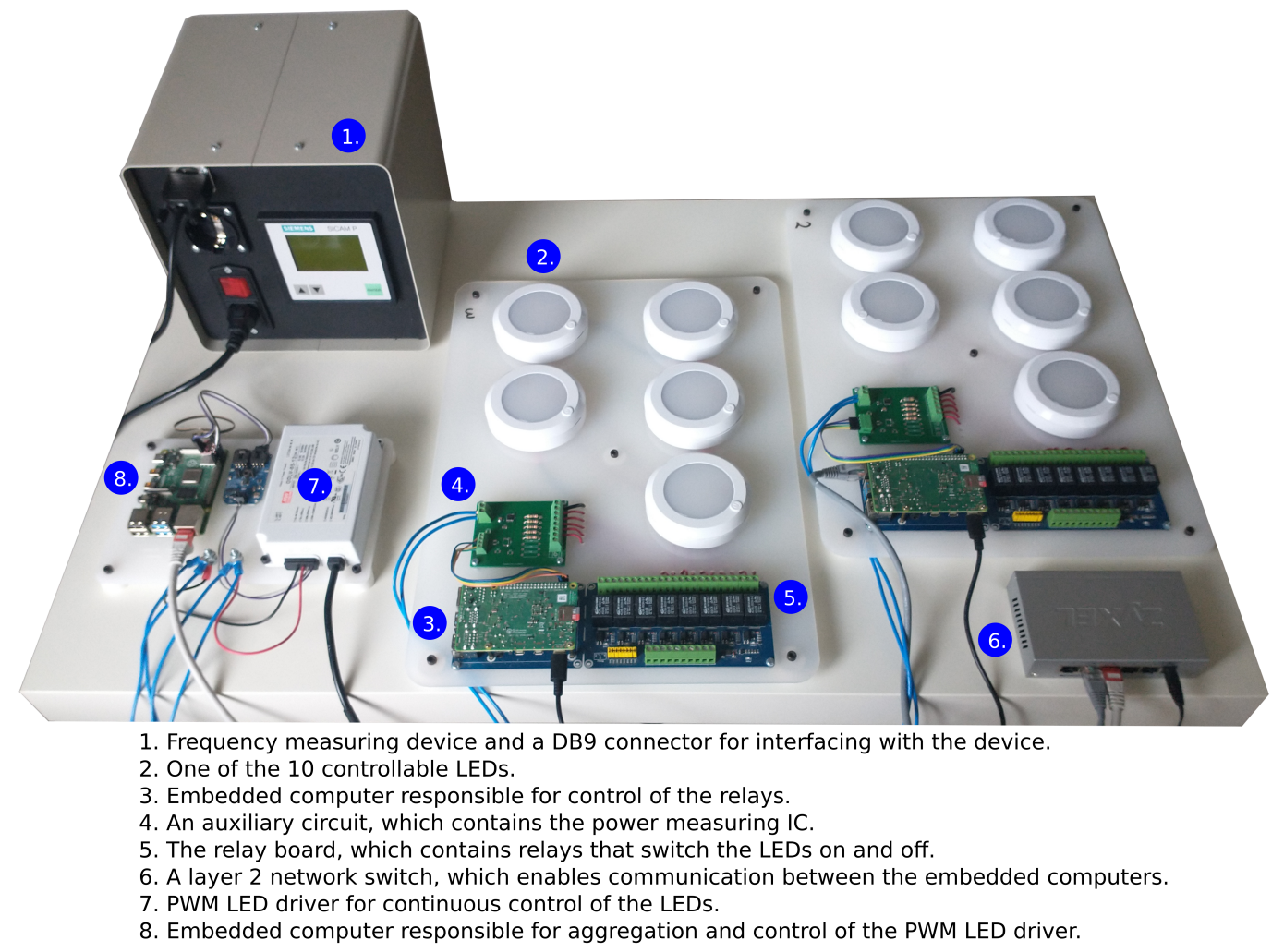

Figure 5. The experimental setup. 


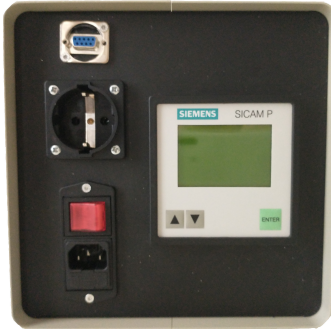

a.

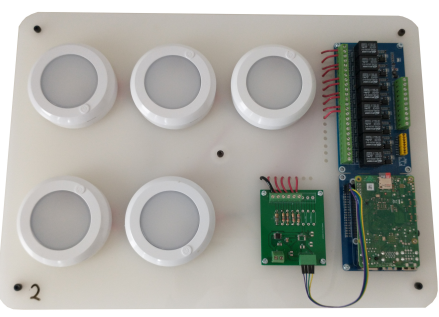

b.

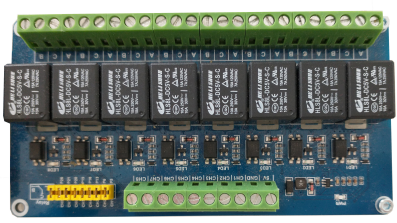

C.

Figure 6. Components of the experimental setup: (a) Sicam P50 [51] frequency measuring device. (b) On-off controllable LED luminaires. (c) Relays that control the LED luminaires.

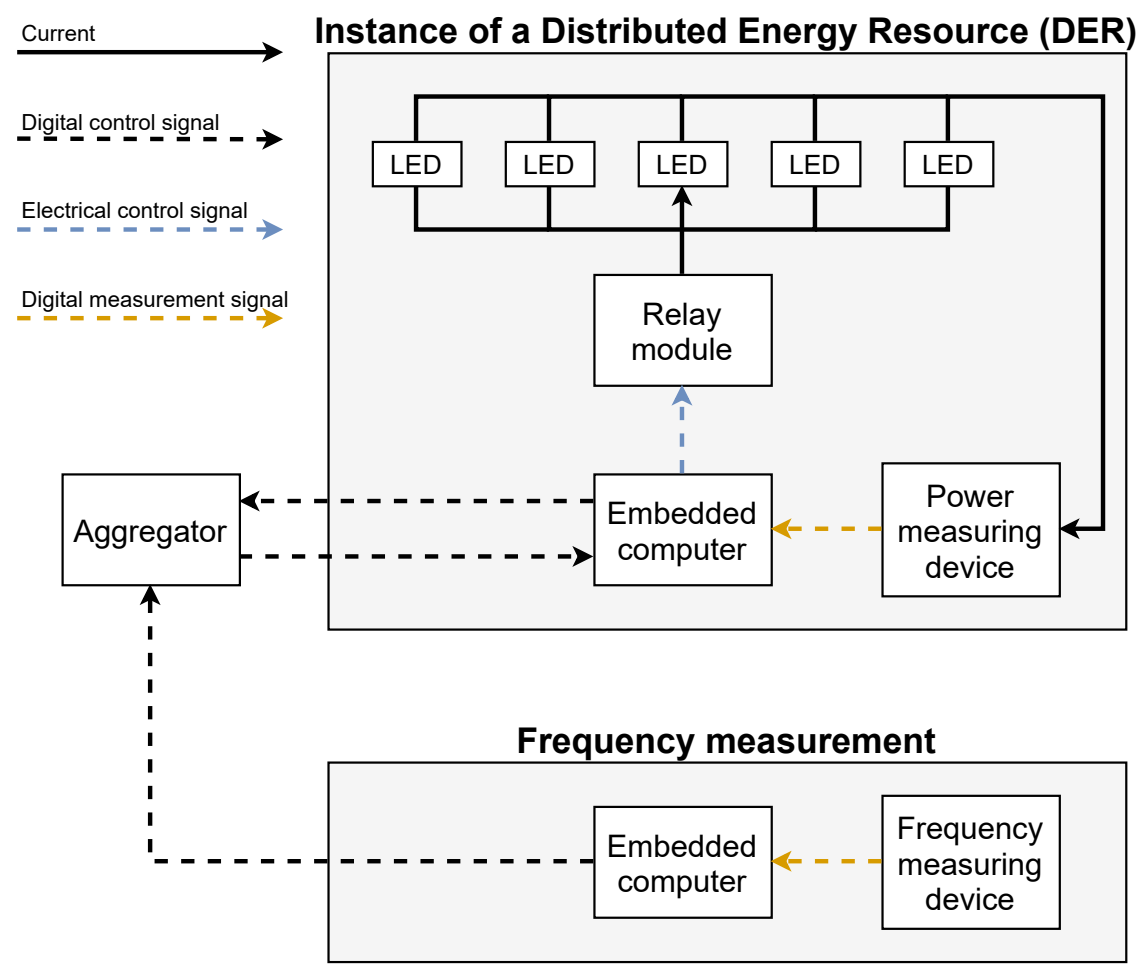

Figure 7. Block diagram of the experimental setup consisting of relay-connected distributed energy resources.

Figure 8 specifies the 'Aggregation/control' activity of the 'Aggregator' in Figure 4. The functions $L(f)$ and $U(f)$ are defined as the lower and upper bounds, respectively, of the blue shaded area of Figure 1. To avoid clutter, Figure 8 is described for the $<50 \mathrm{~Hz}$ scenario of Figure 1. Extension to the $>50 \mathrm{~Hz}$ scenario is straightforward. $P()$ is defined as the total reduction in power consumption from all of the resources that have been disconnected by opening the relay of the resource. $P()$ is expressed as a percentage of the total power capacity specified in the bid that was made to the frequency reserves market. Thus, Figure 8 specifies the real-time operation of the relays in order to ensure that $P()$ never exceeds $U(f)$ and never goes under $L(f)$, where $f$ is the power grid frequency measurement obtained either from the 'Grid frequency measurement' or 'Generated frequency signal' of Figure 3. $N$ is the number of reserve resources under the control of the aggregator. The resources are placed in an ordered list, so that the index $i$ is used to refer to the $i$ th element of the list. $i=0$ corresponds to the first element of the list and $i=N-1$ corresponds to the last element of the list. Any ordering may be used. The functions Available( $i)$, InUse( $(i), P()$, and deadband() referred to in Figure 8 are defined as follows: 
- Available( $i$ ) is defined as a function that returns true or false depending on whether reserve resource $i$ is currently available for frequency control, so that the aggregator has permission to request an operation of its relay;

- InUse $(i)$ is defined as a function that returns true if the aggregator has opened the relay of resource $i$ (denoted in Figure 8 as relay_i) and false otherwise;

- $\quad P()$ is defined as the total power consumption of all of the resources for which InUse $(i)$ is true;

- $\quad$ deadband(f) returns true if the current grid frequency is within a deadband around $50 \mathrm{~Hz}$ at which the technical specification of the market does not require any action to be taken.

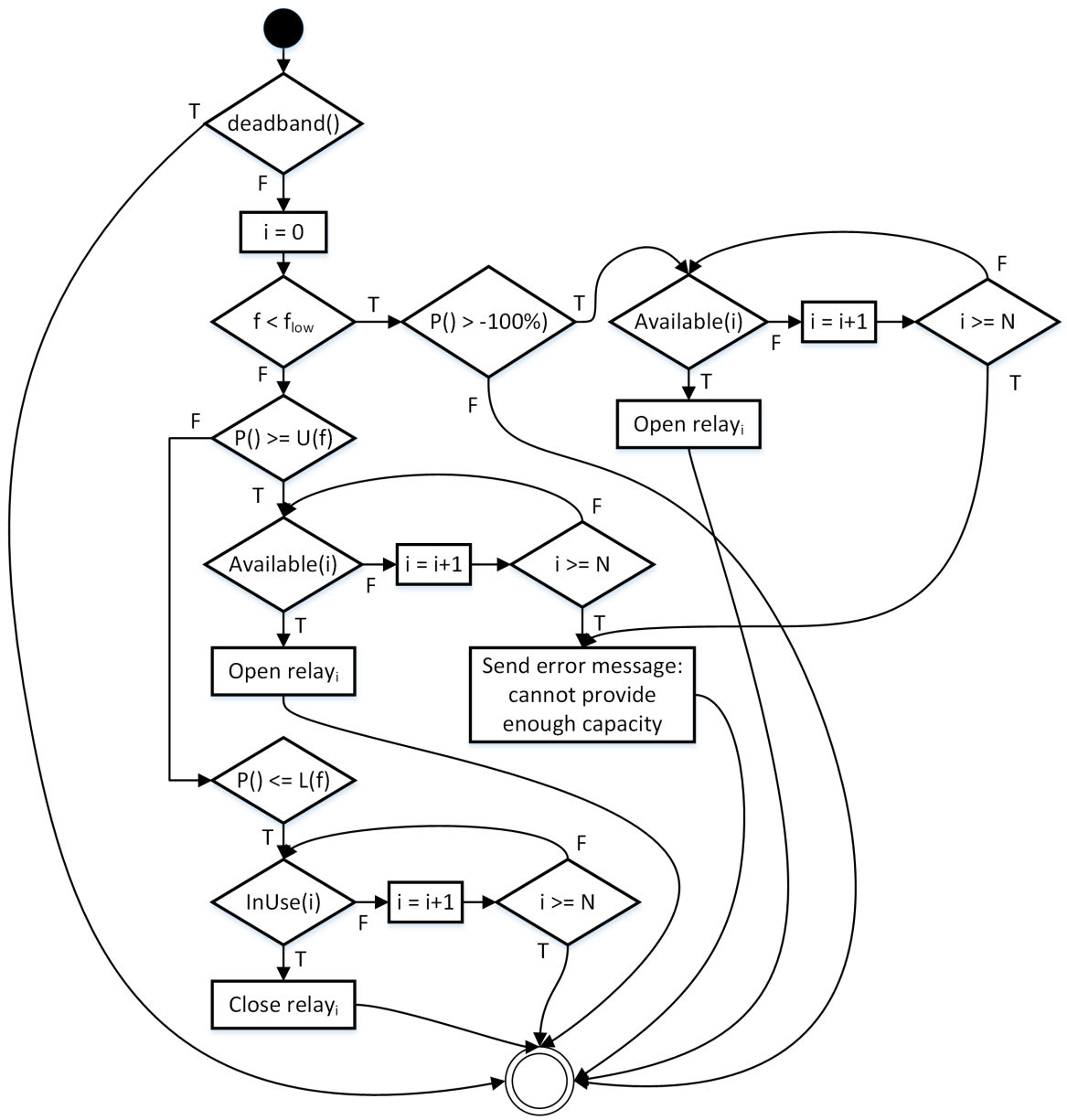

Figure 8. Aggregation of relay-connected distributed energy resources, presented by a UML activity diagram.

The testbed discussed above involved relay control of on-off relays. Additionally, another version of the testbed was implemented with continuously controllable adjustable LEDs. Continuous control of a LED reserve is implemented with a pulse width modulation (PWM) LED driver, which adjusts the target power consumption for the LEDs with a ramp when frequency deviations occur. The slope of the ramp determines how fast the controller is able to react to frequency deviations. A large slope may have a positive impact on the results of the dynamic performance and stability tests; however, frequent changes in luminosity may irritate human users, and, hence, it is beneficial to investigate the impact of different values of the slope to validation results. A constant slope is desirable as it avoids moments of large rate of change of luminosity, but a constant slope can cause unwanted oscillation around the target active power when power measurements are fed back to the controller. Thus, the control algorithm implements P-control when it is within $10 \%$ from 
the target power. Figure 9 shows an example step test with a slope of $1 \%$ reserve capacity per second and no injected delays.

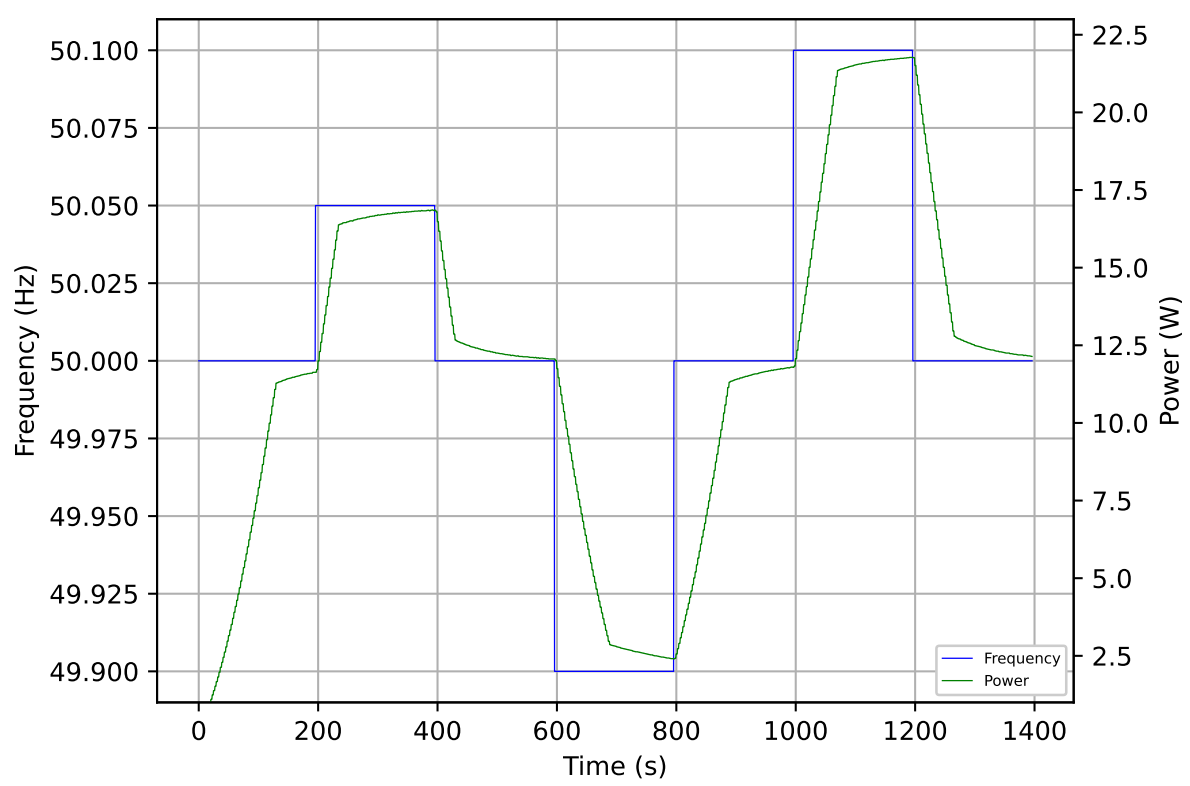

Figure 9. Step response of the continuously controlled LED, where the linear control curve has a slope of $1 \%$ (capacity activation per second).

\section{Results}

Figure 10 shows Bode plots generated by running multiple test sequences on the aggregated system of relays. The plot depicts how the frequency response of the FCR system changes as the injected latency is varied. The injected latencies were chosen, such that round-trip delays (RTDs) were $0,1,2,3,4,5,6,7,8 \mathrm{~s}$. The Bode plot reveals that magnitude is essentially unaffected by the delay. This is to be expected when the aggregator does not require acknowledgement of a received control message. The rate at which the aggregator is able to send control messages is unaffected by the delay; however, the frequency and power measurements received by the aggregator, and the control commands received by the DERs are delayed, resulting in noticeable phase shift relative to the input, especially at high input frequencies.

Figure 11 shows the impact of injected latency to FCR dynamic stability. As per the requirements discussed in Section 3.1.3, the test sequences with RTD of seven or eight seconds did not pass the stability test. The former test sequence failed because the curve enters the stability circle centered at the Nyquist point. The latter crosses the real axis on the left-hand side of the Nyquist point.

Figure 12 shows the impact of injected latency to FCR dynamic performance. The aggregated system of relays has good dynamic performance for all values of the injected delay, partly because the gain is unaffected by the latencies. The sine test with $10 \mathrm{~s}$ period results in slightly higher gain in the test sequence with a RTD of seven seconds. In the open loop Nyquist plot this particular frequency response data point has $180^{\circ}$ phase shift and almost unity gain, which results in positive feedback when the loop is closed. 

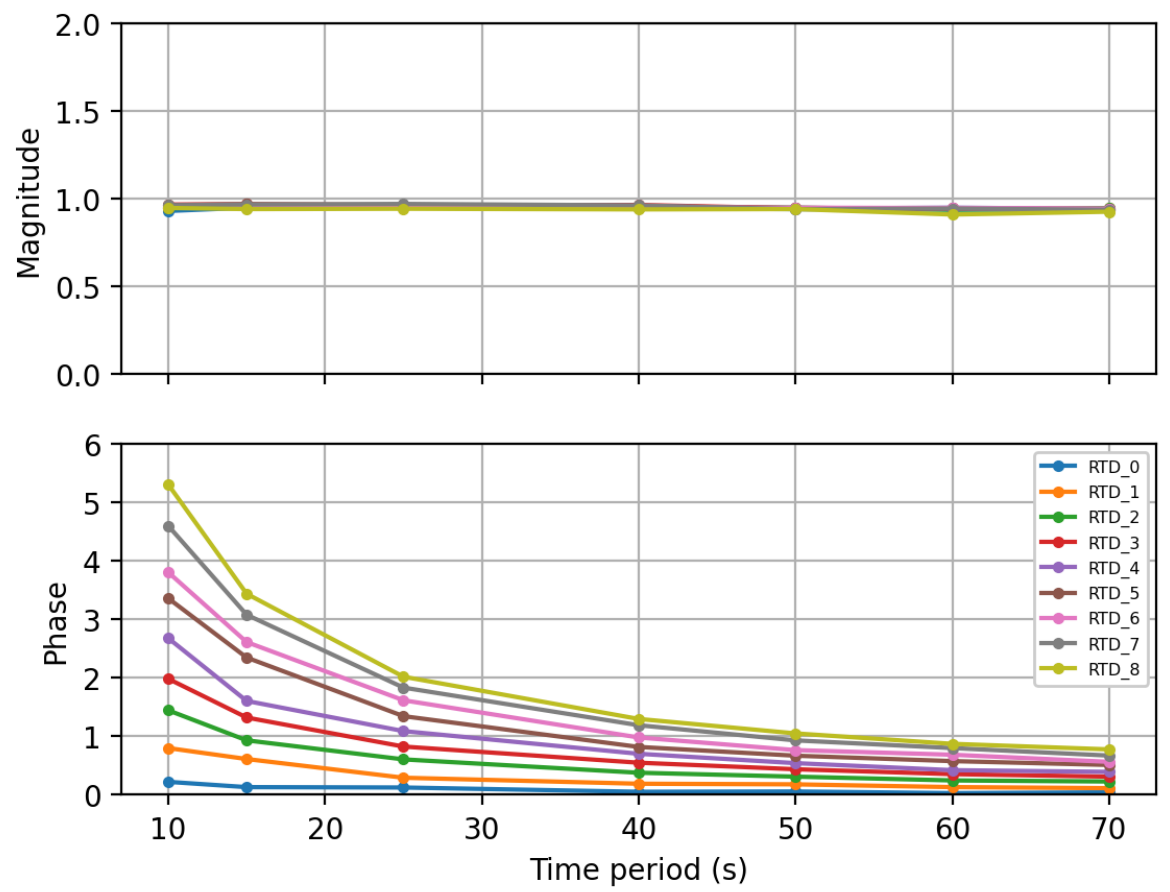

Figure 10. Multiple Bode plots depicting the impact of injected latency to FCR frequency response (phase in radians).

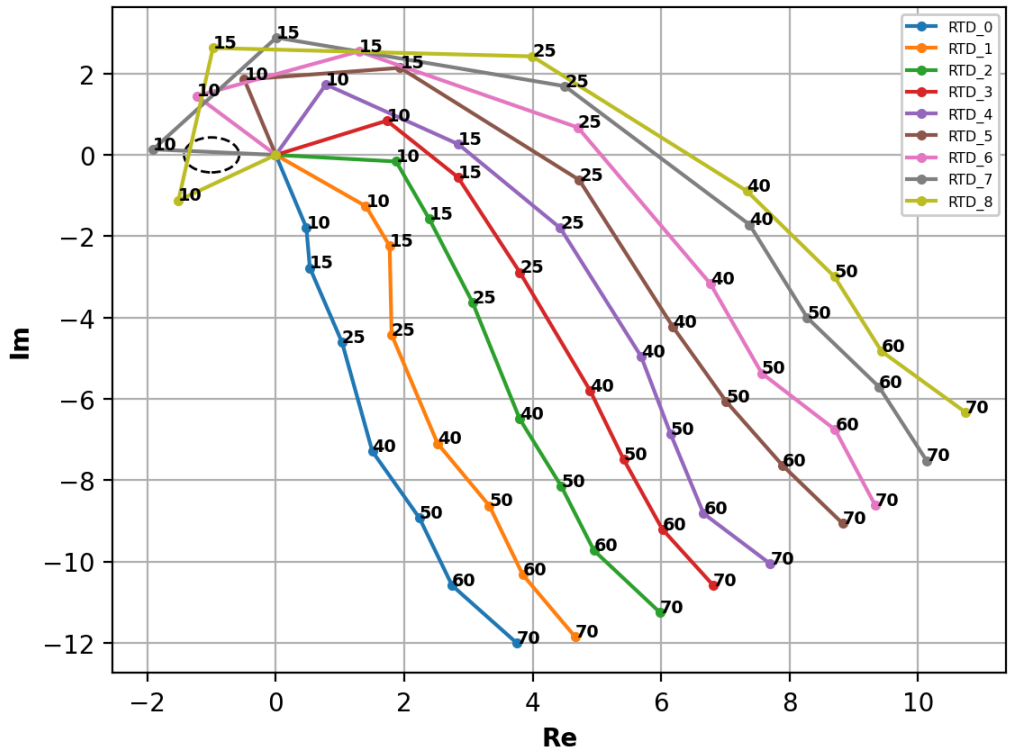

Figure 11. Aggregated plots showing the impact of injected latency to FCR dynamic stability. Each point in the complex plane describes the open loop frequency response for an input signal with the time period indicated by the annotation attached to the point.

Figure 13 shows Bode plots generated by running multiple test sequences on the continuously controllable LEDs. A ramp was used to achieve gradual dimming or brightening of the LEDs. The effect of RTD to magnitude is negligible, whereas a larger slope for the ramp results in higher gain as would be expected, since the response is able to track the input signal faster. For all tested slopes, the gain almost vanished with the lowest time period. In the phase plot, only RTD has significant effect on the curves: higher RTD results in larger phase shift, especially at high input frequencies. 


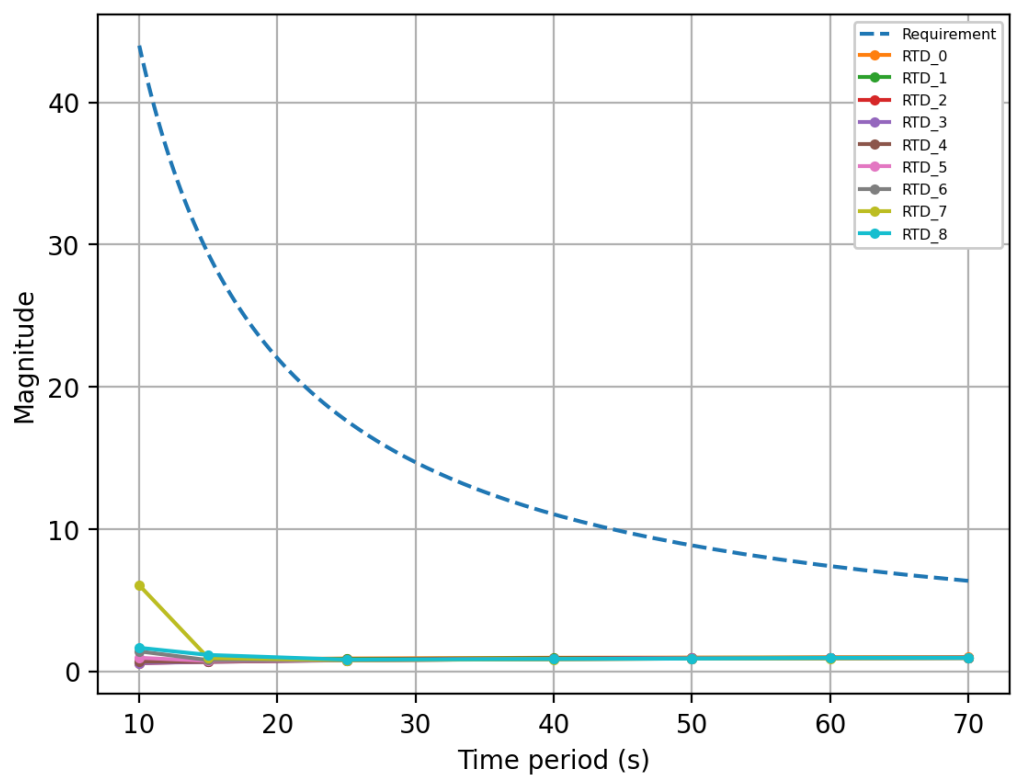

Figure 12. Aggregated plots showing the impact of injected latency to FCR dynamic performance.
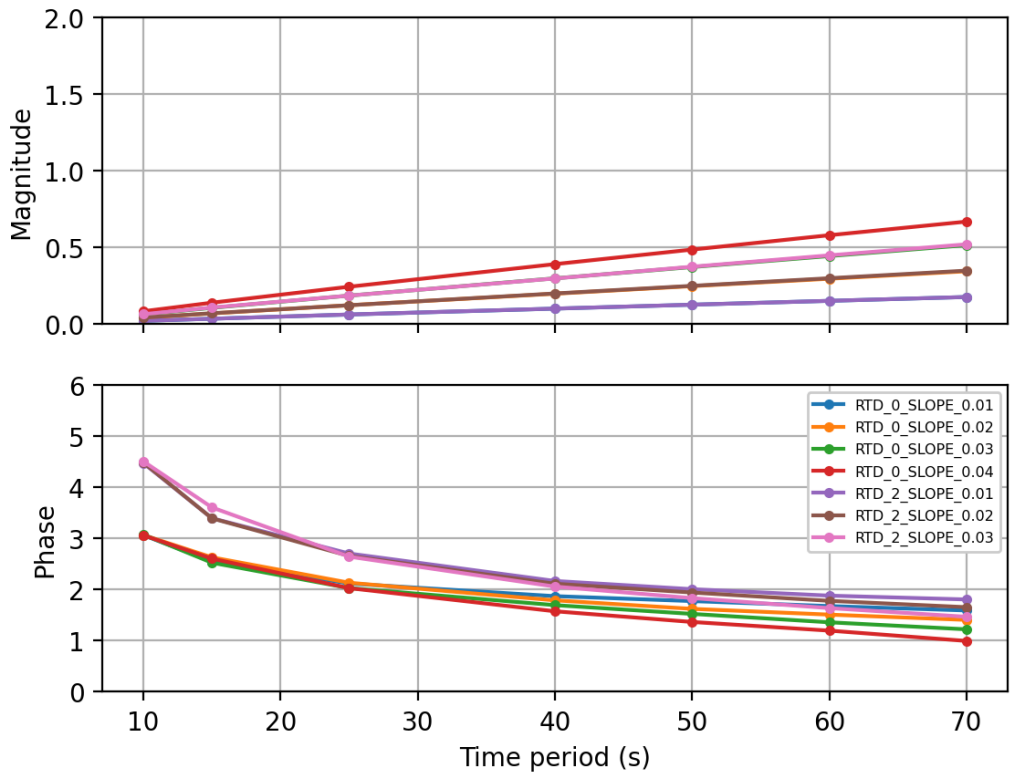

Figure 13. Multiple Bode plots depicting the impact of injected latency and slope of the ramp controller to FCR frequency response (phase in radians).

Figures 14 and 15 show the impact of the injected latencies and slope of the continuous (ramp) controller, described in Section 4, to dynamic performance and stability test results. All tests pass the dynamic stability criterion. However, for continuous control of a LED according to a constant-slope ramp function, the step tests fail before any of the tests based on frequency-domain analysis. The slope must be greater than $1 \%$ of the reserve capacity per second, since it is required that $63 \%$ of the steady-state power activates within one minute after a step input. Hence, only slopes greater than or equal to $1 \%$ were investigated. 


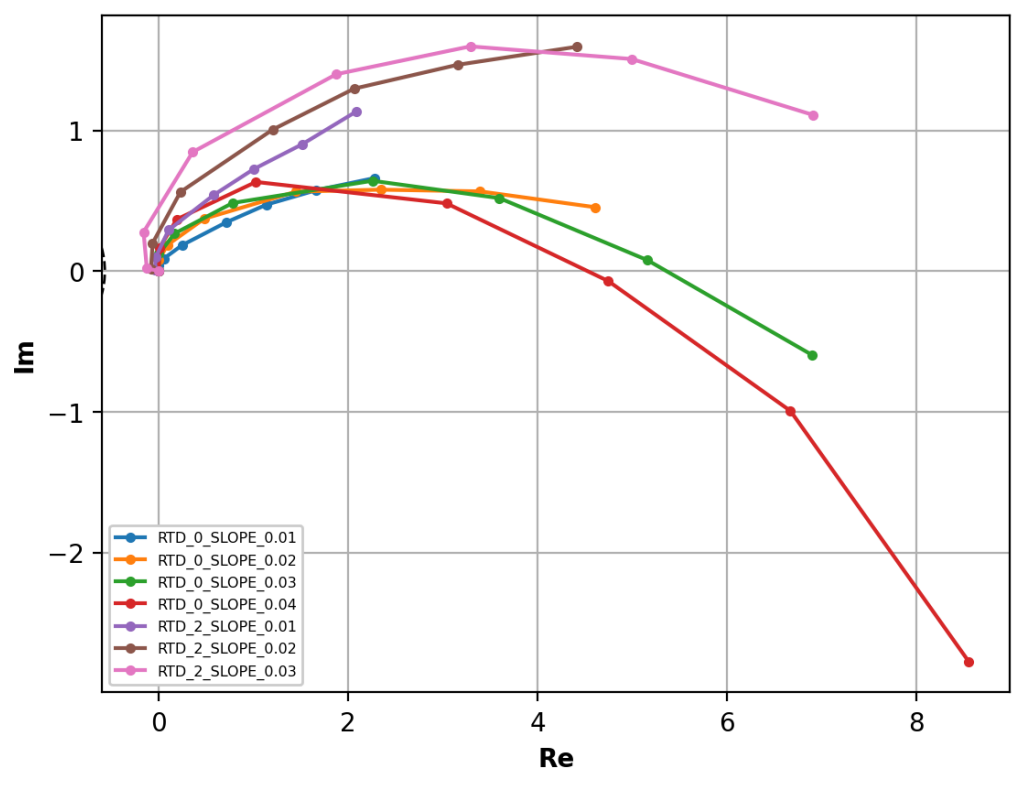

Figure 14. Aggregated plots showing the impact of injected latency and slope of the ramp controller to FCR dynamic stability.

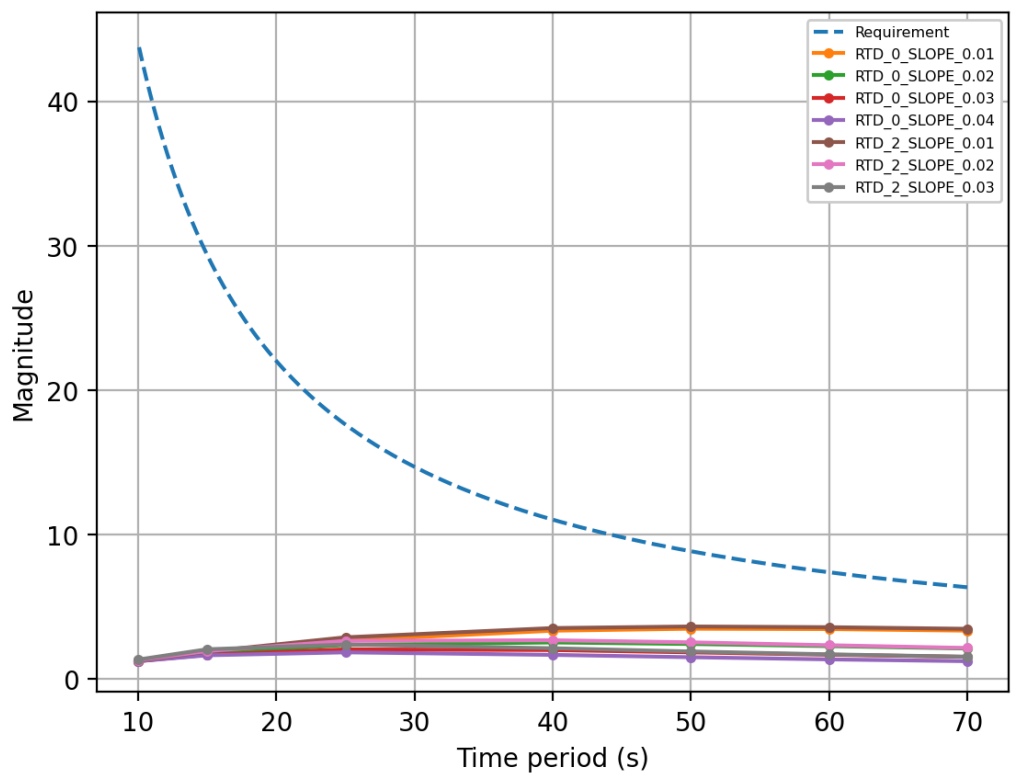

Figure 15. Aggregated plots showing the impact of injected latency and slope of the ramp controller to FCR dynamic performance.

Dynamic performance is clearly worse than in the system of aggregated relays, but the closed-loop gain is still well below the requirement curve, as seen in Figure 15. For test signals with greater time period, the slow ramp leads to slightly decreased dynamic performance, i.e., the dynamic performance curve becomes closer to the requirement curve. RTD seems to have negligible effect on dynamic performance. The dynamic stability requirement is likewise satisfied for all tests. However, Figure 14 reveals that the injection of a two second RTD shifts the phase of the open-loop system such that the Nyquist-curves are rotated anticlockwise towards the left-half side of the complex plane indicating slightly worsening stability. However, the points remain in the right-hand side of the plane or very close to the imaginary axis, and, thus, the stability requirement is satisfied. Higher slope results in larger gain, and, hence, increasing RTD and slope simultaneously could 
eventually lead to instability, if the observed trend continues so that the Nyquist-curves would rotate more towards the critical point, and the gain for low time periods increases.

\section{Discussion}

Section 2 has reviewed the body of research on PFR and pointed out a gap between research and implementation. In the majority of papers, it is not clear what the realtime performance requirements are and whether the solutions would satisfy the real-time requirements of a TSO or ISO. This paper has contributed to bridging the gap between research and implementation through the 3 contributions listed in Section 1:

1. An automated validation methodology has been presented, satisfying the various real-time performance requirements specified by a coalition of four European TSOs. This is offered as a benchmark to other researchers developing PFR applications. In order to repeat the procedure for a different type of energy resource, the user only needs to replace the 'Distributed energy resources providing FCR-N' and 'Aggregator' components of Figure 3;

2. The slowest permissible ramp rate for adjusting power consumption is identified. It is notable that each type of energy resource will have different dynamics which may differ from the LED luminaires studied in this article. However, once the reader has replaced the resource specific control logic, as discussed in bullet 1 , the automated methodology presented in this paper can be used to perform the tests and identify the slowest permissible ramp rate for the type of energy resource being investigated. The result of our experiment was that reasonably parameterized PFR systems could fail the new PFR dynamic requirements, so the matter is of practical significance to designers and implementers;

3. The maximum allowable communication latency was identified experimentally in the case of LED lights that were adjusted immediately. It is notable that the outcome of the tests will also depend on the dynamics of the type of energy resource, and that other types of resources may adjust their power consumption more slowly than LED lights. Thus, once the reader has replaced the resource specific control logic, as discussed in bullet 1, the automated methodology presented in this paper can be used to perform the tests and identify maximum allowable communication latency for the type of resource in question. The result of our experiment was that in some circumstances, the dynamic performance requirements can fail with latencies that have been reported in the literature for NB-IoT systems.

\section{Conclusions}

Running the experiments described in bullets 1-3 of Section 5 is helpful for bridging the gap between research, development, and implementation. It is possible to determine whether the PFR specifications can be met, and whether the power consumption can be adjusted gradually in such a way that does not prematurely shorten the lifespan of the device or irritate human users. It is also possible to assess whether an inexpensive low-power communication medium, such as NB-IoT, will be adequate, or whether it is necessary to invest into, for example, $4 \mathrm{G}$ or $5 \mathrm{G}$ connections. Identifying such factors in research will have the following benefits:

1. Development and implementation proposals can be rejected without investing money to development and research, if research has determined that a proposed novel PFR application cannot meet all PFR real-time requirements;

2. Experts on the specific type of energy resource can be consulted in the research phase, to determine whether or not the proposed control actions are too rapid from the perspective of premature wearing out of the resource;

3. Experts on user comfort and user acceptance can be consulted in the research phase to determine whether or not control actions will be perceived as being too abrupt by users; 
4. Investment into further development is much more likely if a credible research setup has not revealed fatal problems with respect to bullets 1-3. Development resources can be allocated to overcome any minor problems identified with respect to bullets 1-3;

5. Communication technology requirements can be well understood in the research phase. This will guide the choice of a suitable communication technology in the development phase. The feasibility of the system, from the perspective of communications related cost and energy consumption, can thus be assessed before starting the development effort;

6. Implementers will need to prequalify their PFR system before PFR market participation is possible. This can be completed easily, using the automatic setup that has been used in the research and development phase. Any major problems that are found in the implementation phase are very costly for the development effort, if fundamental redesign is needed to meet regulatory requirements. The opportunity to automatically validate the system in research and development phases is expected to significantly mitigate this risk.

LED lights were chosen for demonstration purposes, since it is easy for onlookers to see the effect of the PFR control and to assess whether rapid control actions would be considered disturbing. Further, LED lights can be rapidly adjusted without adverse effects on the lifetime of luminaires, so the testbed could be constructed without implementing constraints that are specific to the type of load. However, such considerations are an important area of further research. HVAC loads are category of energy-intensive loads with significant PFR potential, but such loads have constraints to how often and rapidly they could be controlled, so further research on their feasibility for PFR is needed. For example, a chiller cannot be turned on and off many times per hour. However, if the chiller employs a variable speed compressor, PFR control of the compressor could be feasible. Unlike LED lights, in which the impact on the indoor or outdoor environment is immediate, the effect of PFR control of HVAC on the indoor environment is delayed due to the thermal mass of the building, and these delays can vary from one building to the next. In addition to HVAC, electric vehicle chargers are an interesting application area for PFR. From a power electronics perspective, meeting the PFR performance and stability requirements is possible. However, the impact of the PFR control actions on battery degradation is an area of further research.

Author Contributions: Conceptualization, S.S.; methodology, N.K.; software, N.K.; validation, N.K.; formal analysis, N.K.; investigation, N.K.; resources, V.V.; writing, S.S. and N.K.; visualization, S.S. and N.K.; supervision, S.S. and V.V.; project administration, S.S.; funding acquisition, S.S. All authors have read and agreed to the published version of the manuscript.

Funding: This research received no external funding.

Institutional Review Board Statement: Not applicable.

Informed Consent Statement: Not applicable.

Data Availability Statement: Data are contained within the article.

Conflicts of Interest: The authors declare no conflicts of interest.

\section{References}

1. Samad, T.; Koch, E.; Stluka, P. Automated Demand Response for Smart Buildings and Microgrids: The State of the Practice and Research Challenges. Proc. IEEE 2016, 104, 726-744. [CrossRef]

2. Bokhari, H.; Westermann, D. Techno-Economic Evaluation of Load Frequency Control Systems for Electric Vehicle Fleet Integration. IET Renew. Power Gener. 2017, 11, 819-826. [CrossRef]

3. Majumder, S.; Agalgaonkar, A.; Khaparde, S.; Perera, S.; Kulkarni, S.; Ciufo, P. Allowable Delay Heuristic in Provision of Primary Frequency Reserve in the Future Power System. IEEE Trans. Power Syst. 2020, 35, 1231-1241. [CrossRef] 
4. ENTSO-E (European Network of Transmission System Operators for Electricity). Technical Requirements for Frequency Containment Reserve Provision in the Nordic Synchronous Area, Version for the Pilot Phase. 2021. Available online: https: / / www.epressi.com/media/userfiles/107305/1617167107/fcr-technical-requirements-for-pilot-phase-v0.9.pdf (accessed on 5 April 2021).

5. Fingrid Oyj. The Technical Requirements and the Prequalification Process of Frequency Containment Reserves (FCR). 2021. Available online: https://www.fingrid.fi/globalassets/dokumentit/en/electricity-market/reserves/fcr-liite2---teknistenvaatimusten-todentaminen-ja-hyvaksyttamisprosessi_en.pdf (accessed on 8 July 2021).

6. Papadogiannis, K.; Hatziargyriou, N. Optimal Allocation of Primary Reserve Services in Energy Markets. IEEE Trans. Power Syst. 2004, 19, 652-659. [CrossRef]

7. Liu, C.; Du, P. Participation of Load Resources in Day-Ahead Market to Provide Primary-Frequency Response Reserve. IEEE Trans. Power Syst. 2018, 33, 5041-5051. [CrossRef]

8. Liu, H.; Zhang, C.; Peng, X.; Zhang, S. Configuration of an Energy Storage System for Primary Frequency Reserve and Inertia Response of the Power Grid. IEEE Access 2021, 9, 41965-41975. [CrossRef]

9. Tetri, E.; Bozorg, S.; Räsänen, R.S.; Baumgartner, H.; Vaaja, M.; Sierla, S.; Tähkämö, L.; Virtanen, J.P.; Kurkela, M.; Ikonen, E.; et al Tutorial: Road Lighting for Efficient and Safe Traffic Environments. LEUKOS J. Illum. Eng. Soc. 2017, 13, 223-241. [CrossRef]

10. Baniya, R.; Maksimainen, M.; Sierla, S.; Pang, C.; Yang, C.W.; Vyatkin, V. Smart indoor lighting control: Power, illuminance, and colour quality. In Proceedings of the 2014 IEEE 23rd International Symposium on Industrial Electronics (ISIE), Istanbul, Turkey, 1-4 June 2014; pp. 1745-1750. [CrossRef]

11. Yang, C.W.; Nefedov, E.; Sierla, S.; Flikkema, P. Vehicle and pedestrian aware street lighting automation. In Proceedings of the 2015 IEEE 13th International Conference on Industrial Informatics (INDIN), Cambridge, UK, 22-24 July 2015; pp. 1269-1274. [CrossRef]

12. Nefedov, E.; Yang, C.W.; Maksimainen, M.; Sierla, S.; Flikkema, P. Energy efficient traffic-based street lighting automation. In Proceedings of the 2014 IEEE 23rd International Symposium on Industrial Electronics (ISIE), Istanbul, Turkey, 1-4 June 2014; pp. 1718-1723. [CrossRef]

13. Manner, P.; Alapera, I.; Honkapuro, S. Domestic heat pumps as a source of primary frequency control reserve. In Proceedings of the 2020 17th International Conference on the European Energy Market (EEM), Stockholm, Sweden, 16-18 September 2020; pp. 1-5. [CrossRef]

14. Manner, P.; Salmelin, J.; Honkapuro, S.; Alapera, I.; Annala, S. A novel method to utilize direct electrical space heating for explicit demand response purposes-proof of concept. In Proceedings of the 2020 IEEE PES Innovative Smart Grid Technologies Europe (ISGT-Europe), The Hague, Netherlands, 26-28 October 2020; pp. 86-90. [CrossRef]

15. Sultania, A.; Mahfoudhi, F.; Famaey, J. Real-Time Demand-Response using NB-IoT. IEEE Internet Things J. 2020, 7, $11863-11872$. [CrossRef]

16. Giovanelli, C.; Kilkki, O.; Sierla, S.; Seilonen, I.; Vyatkin, V. Task Allocation Algorithm for Energy Resources Providing Frequency Containment Reserves. IEEE Trans. Ind. Inform. 2019, 15, 677-688. [CrossRef]

17. Giovanelli, C.; Liu, X.; Sierla, S.; Vyatkin, V.; Ichise, R. Towards an aggregator that exploits big data to bid on frequency containment reserve market. In Proceedings of the IECON 2017—43rd Annual Conference of the IEEE Industrial Electronics Society, Beijing, China, 29 October-1 November 2017; pp. 7514-7519. [CrossRef]

18. Giovanelli, C.; Sierla, S.; Ichise, R.; Vyatkin, V. Exploiting Artificial Neural Networks for the Prediction of Ancillary Energy Market Prices. Energies 2018, 11, 1906. [CrossRef]

19. Nefedov, E.; Sierla, S.; Vyatkin, V. Internet of Energy Approach for Sustainable Use of Electric Vehicles as Energy Storage of Prosumer Buildings. Energies 2018, 11, 2165. [CrossRef]

20. Lu, R.; Bai, R.; Huang, Y.; Li, Y.; Jiang, J.; Ding, Y. Data-driven real-time price-based demand response for industrial facilities energy management. Appl. Energy 2021, 283, 116291. [CrossRef]

21. Waseem, M.; Lin, Z.; Liu, S.; Zhang, Z.; Aziz, T.; Khan, D. Fuzzy compromised solution-based novel home appliances scheduling and demand response with optimal dispatch of distributed energy resources. Appl. Energy 2021, 290, 116761. [CrossRef]

22. El Geneidy, R.; Howard, B. Contracted energy flexibility characteristics of communities: Analysis of a control strategy for demand response. Appl. Energy 2020, 263, 114600. [CrossRef]

23. Stathopoulos, P.; Sleem, T.; Paschereit, C. Steam generation with stoichiometric combustion of $\mathrm{H}_{2} / \mathrm{O}_{2}$ as a way to simultaneously provide primary control reserve and energy storage. Appl. Energy 2017, 205, 692-702. [CrossRef]

24. Lee, R.; Homan, S.; Dowell, N.; Brown, S. A closed-loop analysis of grid scale battery systems providing frequency response and reserve services in a variable inertia grid. Appl. Energy 2019, 236, 961-972. [CrossRef]

25. Oudalov, A.; Chartouni, D.; Ohler, C. Optimizing a Battery Energy Storage System for Primary Frequency Control. IEEE Trans. Power Syst. 2007, 22, 1259-1266. [CrossRef]

26. Díaz-González, F.; Hau, M.; Sumper, A.; Gomis-Bellmunt, O. Participation of wind power plants in system frequency control: Review of grid code requirements and control methods. Renew. Sustain. Energy Rev. 2014, 34, 551-564. [CrossRef]

27. Hasanpor Divshali, P.; Evens, C. Optimum Operation of Battery Storage System in Frequency Containment Reserves Markets. IEEE Trans. Smart Grid 2020, 11, 4906-4915. [CrossRef]

28. Herre, L.; Tomasini, F.; Paridari, K.; Soder, L.; Nordström, L. Simplified model of integrated paper mill for optimal bidding in energy and reserve markets. Appl. Energy 2020, 279, 115857. [CrossRef] 
29. Mashlakov, A.; Pournaras, E.; Nardelli, P.; Honkapuro, S. Decentralized cooperative scheduling of prosumer flexibility under forecast uncertainties. Appl. Energy 2021, 290, 116706. [CrossRef]

30. Engels, J.; Claessens, B.; Deconinck, G. Techno-economic analysis and optimal control of battery storage for frequency control services, applied to the German market. Appl. Energy 2019, 242, 1036-1049. [CrossRef]

31. Braeuer, F.; Rominger, J.; Mckenna, R.; Fichtner, W. Battery storage systems: An economic model-based analysis of parallel revenue streams and general implications for industry. Appl. Energy 2019, 239, 1424-1440. [CrossRef]

32. Hosseini, S.A.; Toubeau, J.F.; De Greve, Z.; Vallee, F. An advanced day-ahead bidding strategy for wind power producers considering confidence level on the real-time reserve provision. Appl. Energy 2020, 280, 115973. [CrossRef]

33. Diaz-Londono, C.; Enescu, D.; Ruiz, F.; Mazza, A. Experimental modeling and aggregation strategy for thermoelectric refrigeration units as flexible loads. Appl. Energy 2020, 272, 115065. [CrossRef]

34. Alaperä, I.; Honkapuro, S.; Paananen, J. Data centers as a source of dynamic flexibility in smart girds. Appl. Energy 2018, 229, 69-79. [CrossRef]

35. Pusceddu, E.; Zakeri, B. Synergies between energy arbitrage and fast frequency response for battery energy storage systems. Appl. Energy 2021, 283, 116274. [CrossRef]

36. ENTSO-E (European Network of Transmission System Operators for Electricity). Supporting Document on Technical Requirements for Frequency Containment Reserve Provision in the Nordic Synchronous Area, Version for the Pilot Phase. 2021. Available online: https:/ / www.epressi.com/media/userfiles/107305/1617167107/fcr-supporting-document-for-pilot-phasev0.9.pdf (accessed on 5 April 2021).

37. Bruns, A.; Kornstädt, A.; Wichmann, D. Web Application Tests with Selenium. IEEE Softw. 2009, 26, 88-91. [CrossRef]

38. Ambler, S. Test-Driven Development of Relational Databases. IEEE Softw. 2007, 24, 37-43. [CrossRef]

39. Remmel, H.; Paech, B.; Bastian, P.; Engwer, C. System Testing a Scientific Framework Using a Regression-Test Environment. Comput. Sci. Eng. 2012, 14, 38-45. [CrossRef]

40. Strandberg, P.; Afzal, W.; Ostrand, T.; Weyuker, E.; Sundmark, D. Automated System-Level Regression Test Prioritization in a Nutshell. IEEE Softw. 2017, 34, 30-37. [CrossRef]

41. Guerra, E. Designing a Framework with Test-Driven Development: A Journey. IEEE Softw. 2014, 31, 9-14. [CrossRef]

42. Crispin, L. Driving Software Quality: How Test-Driven Development Impacts Software Quality. IEEE Softw. 2006, 23, 70-71. [CrossRef]

43. Ulewicz, S.; Schütz, D.; Vogel-Heuser, B. Software changes in factory automation: Towards automatic change based regression testing. In Proceedings of the IECON 2014 - 40th Annual Conference of the IEEE Industrial Electronics Society, Dallas, TX, USA, 29 October-1 November 2014; pp. 2617-2623. [CrossRef]

44. Ulewicz, S.; Vogel-Heuser, B. System regression test prioritization in factory automation: Relating functional system tests to the tested code using field data. In Proceedings of the IECON 2016 - 42nd Annual Conference of the IEEE Industrial Electronics Society, Florence, Italy, 23-26 October 2016; pp. 4619-4626. [CrossRef]

45. Hametner, R.; Winkler, D.; Zoitl, A. Agile Testing Concepts Based on Keyword-driven Testing for Industrial Automation Systems. In Proceedings of the IECON 2012-38th Annual Conference on IEEE Industrial Electronics Society, Montreal, QC, Canada, 25-28 October 2012; pp. 3727-3732. [CrossRef]

46. Dowdeswell, B.; Sinha, R.; MacDonell, S. Diagnosable-by-Design Model-Driven Development for IEC 61499 Industrial CyberPhysical Systems. In Proceedings of the IECON 2020 The 46th Annual Conference of the IEEE Industrial Electronics Society, Singapore, 18-21 October 2020; pp. 2183-2188. [CrossRef]

47. Hametner, R.; Winkler, D.; Ostreicher, T.; Biffl, S.; Zoitl, A. The adaptation of test-driven software processes to industrial automation engineering. In Proceedings of the 2010 8th IEEE International Conference on Industrial Informatics, Osaka, Japan, 13-16 July 2010; pp. 921-927. [CrossRef]

48. Cha, S.; Ulewicz, S.; Vogel-Heuser, B.; Weigl, A.; Ulbrich, M.; Beckert, B. Generation of monitoring functions in production automation using test specifications. In Proceedings of the 2017 IEEE 15th International Conference on Industrial Informatics (INDIN), Emden, Germany, 24-26 July 2017; pp. 339-344. [CrossRef]

49. Peltola, J.; Sierla, S.; Aarnio, P.; Koskinen, K. Industrial evaluation of functional Model-Based Testing for process control applications using CAEX. In Proceedings of the 2013 IEEE 18th Conference on Emerging Technologies and Factory Automation (ETFA), Cagliari, Italy, 10-13 September 2013; pp. 1-8. [CrossRef]

50. Peltola, J.; Sierla, S.; Vyatkin, V. Adapting Keyword driven test automation framework to IEC 61131-3 industrial control applications using PLCopen XML. In Proceedings of the 2014 IEEE Emerging Technology and Factory Automation (ETFA), Barcelona, Spain, 16-19 September 2014; pp. 1-8. [CrossRef]

51. Siemens, A.G. Power Meter Sicam P 7KG7750/55 Manual. 2013. Available online: https://support.industry.siemens.com/cs/ attachments/109752179/MAN_SICAM_P_7KG775x_EN.pdf (accessed on 14 October 2021).

52. Texas Instruments. INA260 Precision Digital Current and Power Monitor With Low-Drift, Precision Integrated Shunt. 2016. Available online: https:/ /www.ti.com/lit/ds/symlink/ina260.pdf (accessed on 14 October 2021). 